\title{
Analisis Problem Solving Skills Siswa Pada Materi Lingkungan
}

\author{
Nadya Utary, Nur Eka Kusuma Hindrasti*, Trisna Amelia \\ Program Studi Pendidikan Biologi, Universitas Maritim Raja Ali Haji \\ Alamat email koresponden: nurekakh2017@umrah.ac.id \\ diterima: 15 Agustus 2020, disetujui: 22 Agustus 2020, dipublikasikan: 30 September 2020
}

\begin{abstract}
The purpose of the research was to find out the level of the students' problem solving skills on environmental material at $X$ class of MAN Bintan. The researcher applied descriptive quantitative approach as method for analyzing the data. Sampling in this study using Total Sampling technique with the sampel consisted of 59 students. This instrument is used to collect students' problem solving skills through six aspects to Chang \& Kelly with 6 items essay and feature interviews. The data were analyzed with statistical rule in percentage. Based on the results of data analyze shows that a $77 \%$ rate highly classified. The researcher concluded that student at $X$ class MAN Bintan has good problem solving skills. However, it still needs training and guidance to develop problem solving skills.
\end{abstract}

Keywords: biology learning, environmental material, problem solving skills.

\section{PENDAHULUAN}

Terdapat berbagai macam masalah yang ditemui di kehidupan sehari-hari. Oleh sebab itu, manusia harus berpikir untuk menyelesaikan masalah tersebut. Diperlukannya problem solving skills diperkuat dengan pendapat Paidi (2011), problem solving skills membantu siswa membuat keputusan yang tepat, sistematis, logis, dan mempertimbangkan dari berbagai sudut pandang. Bagi siswa, problem solving skills sangat diperlukan karena akan digunakan ketika terjun langsung di masyarakat salah satunya dunia kerja.

$$
\text { National Reasearch Council }
$$

mengemukakan bahwa dunia pekerjaan saat ini banyak memerlukan keterampilan sains dan problem solving. Namun, literasi sains dan problem solving di Indonesia masih rendah. Menurut studi PISA (Program International for Student Assesment) tahun 2015, Indonesia berada diperingkat ke-62 dari 70 negara dengan rata-rata 403 (OECD, 2016). Dengan adanya hasil ini membuktikan bahwa kualitas pembelajaran di Indonesia masih belum maksimal dan hasil ini menjadi peringatan bahwa Indonesia masih punya tugas untuk meningkatkan problem solving skills siswa.

Peningkatan problem solving skills siswa, guru memiliki peran yang sangat penting, dengan cara memberikan fasilitas dalam pembelajaran yang membantu siswa dalam mengembangkan problem solving skills siswa. Untuk itu, guru dianjurkan menggunakan model dan strategi mengajar yang berorientasi pada cara menyelesaikan suatu masalah. Problem solving skills merupakan salah satu kemampuan kompleks yang seharusnya diajarkan di setiap jenjang pendidikan. Problem solving skills dianggap kompleks, karena meliputi keterampilan berpikir seperti mengamati, mendeskripsi, menganalisis, mengklasifikasikan, menarik kesimpulan dan membuat generalisasi berdasarkan hasil pengolahan data dan informasi (Nasution, 2009).

Berdasarkan wawancara dengan guru di MAN Bintan diperoleh informasi bahwa belum diketahui tingkat problem solving 
skills siswa. Dalam kegiatan pembelajaran siswa kurang mampu memberikan solusi terbaik dalam menyelsesaikan masalah dalam sebuah wacana yang diberikan guru. Guru sudah memberikan fasilitas dalam kegiatan pembelajaran dalam mengembangkan problem solving skills siswa seperti strategi pembelajaran dan lembar kerja siswa terkait dalam memecahkan masalah namun masih kurang berjalan secara efektif. Guru juga belum melakukan penilaian khusus terhadap problem solving skills siswa sehingga guru belum mengetahui gambaran problem solving skills siswa. Maka itu, perlu dikaji untuk menentukan tingkat problem solving skills siswa dengan analisis khusus dengan memberikan tes untuk memberikan stimulus kepada siswa dalam memecahkan masalah.

Pertanyaan penelitian ini yaitu "Bagaimana tingkatan problem solving skills siswa pada materi lingkungan di kelas $\mathrm{X}$ MAN Bintan?". Sehingga tujuan penelitian ini dilakukan untuk mengetahui tingkatan problem solving skills siswa pada materi lingkungan di kelas X MAN Bintan.

\section{METODE}

Penelitian yang dilakukan oleh peneliti dilaksanakan di sekolah MAN Bintan pada bulan Mei hingga Juli pada Tahun Ajaran 2018/2019. Penelitian merupakan jenis penelitian deskriptif dan menggunakan pendekatan kuantitatif. Dalam pengambilan sampel menggunakan teknik total sampling dengan jumlah sampel sebanyak 59 orang siswa. Penelitian ini dilakukan dengan 2 tahap penelitian yaitu tahap persiapan dan tahap pelaksanaan. Untuk teknik mengumpulkan data digunakan instumen tes dan wawancara problem solving skills. Instrumen tes digunakan dalam bentuk soal uraian. Teknik analisis data menggunakan rumus statistik berupa persentase. Setelah itu, data tersebut dijumlahkan rata-rata persentase pencapaian problem solving skills berdasarkan kriteria yang telah ditetapkan pada Tabel 1:

Tabel 1. Kriteria Hasil Analisis Tes Problem Solving Skills

\begin{tabular}{cc}
\hline Persentase & Klasifikasi \\
\hline $81 \%-100 \%$ & Sangat Tinggi \\
$66 \%-80 \%$ & Tinggi \\
$56 \%-65 \%$ & Cukup \\
$41 \%-55 \%$ & Rendah \\
$0 \%-40 \%$ & Sangat Rendah \\
\hline
\end{tabular}

\section{HASIL DAN PEMBAHASAN}

Dari hasil analisis, diperoleh rata-rata skor problem solving skills siswa dengan persentase $77 \%$. Hal ini menunjukkan bahwa problem solving skills siswa berada pada tingkat tinggi. Uraian hasil tes problem solving skills siswa dapat dilihat pada Tabel 2 di bawah ini.

Tabel 2. Hasil Tes Problem Solving Skills

\begin{tabular}{lcc}
\multicolumn{1}{c}{ Aspek } & Persentase (\%) & Kategori \\
\hline Define the problem (mendefinisikan masalah) & 80 & Tinggi \\
Analyze potential causes (analisis sebab-sebab masalah) & 80 & Tinggi \\
Identify possible solutions (identifikasi kemungkinan & 85 & Sangat Tinggi \\
solusi) & & Tinggi \\
Select the best solution (memilih solusi terbaik) & 80 & Cukup \\
$\begin{array}{l}\text { Develop anaction plan (menyusun rencana tindakan) } \\
\text { Iimplement solution and evaluate progress }\end{array}$ & 58 & Rendah \\
(mengimplementasikan solusi dan mengevaluasi \\
perkembangan)
\end{tabular}

journal homepage : http://journal.univetbantara.ac.id/index.php/JBL/ 
Berdasarkan Tabel 2 menunjukkan bahwa dari 4 aspek pertama memiliki persentase yang tinggi terutama pada aspek identify possible solutions (identifikasi kemungkinan solusi) dan aspek implement solution and evaluateprogress (mengimplementasikan solusi dan mengevaluasi perkembangan) merupakan aspek terendah. Hal ini menunjukkan bahwa siswa mengalami kesulitan dalam menyusun rencana tindakan dan menerapkan rencana tindakan dalam menyelesaikan masalah.

Penelitian ini mengukur problem solving skills siswa yang mengacu pada enam aspek keterampilan menurut Chang \& Kelly, meliputi define the problem (mendefenisikan masalah), analyze potential causes (analisis sebab-sebab masalah), identify possible solutions (identifikasi kemungkinan solusi), select the best solution (memilih solusi terbaik), develop anaction plan (menyusun rencana tindakan), implement solution and evaluate progress (mengimplemntasikan tindakan dan mengevaluasi perkembangan).

Hasil penelitian yang diperoleh bahwa dari 59 orang siswa MAN Bintan diberikan tes soal problem solving skills mengenai materi Lingkungan diperoleh $80 \%$ siswa mampu untuk mendefenisikan masalah (define the problem), $80 \%$ siswa mampu menganalisis sebab-sebab masalah (analyze potential causes), $85 \%$ siswa mampu mengidentifikasi kemungkinan solusi-solusi terbaik (identify possible solution), $80 \%$ siswa mampu untuk memilih solusi terbaik berdasarkan solusi alternative yang dijabarkan (select the best solution), 58\% siswa mampu menyusun rencana tindakan sesuai dengan solusi terbaik pilih (develop anaction plan), $43 \%$ siswa mampu menerapkan tindakan dan mengevaluasi hasil dari tindakan yang diterapkan (implement solution and evaluate progress). Sehingga diperoleh rerata persentase problem solving skills siswa sebesar $77 \%$ dengan kategori tinggi.

Aspek mendefinisikan masalah (define the problem) termasuk aspek yang berada pada tingkat tinggi, secara keseluruhan siswa sudah mampu untuk menemukan masalah dan memusatkan suatu masalah sehingga mudah untuk dipecahkan. Siswa secara keseluruhan dapat menemukan pokok-pokok permasalahan yang sesuai dengan permasalahan yang terjadi pada wacana dan berhubungan dengan konsep lingkungan, siswa mampu menyusun kalimat dengan kalimat sendiri dan menjelaskan dengan alasan yang tepat.

Menurut hasil wawancara, siswa mengatakan bahwa cara dalam menemukan pokok-pokok permasalahan adalah dengan membaca setiap ide pokok utama dalam paragraf di wacana. Hasil penelitian ini juga sejalan dengan penelitian yang dilakukan oleh Pratiwi (2014) yang memperoleh kesimpulan bahwa indikator mengidentifikasi masalah termasuk kedalam kategori sangat tinggi dengan persentase $96,91 \%$ dengan pernyataan bahwa secara keseluruhan siswa mampu untuk mengidentifikasi masalah sesuai dengan permasalahan yang terjadi pada pertanyaan yang disajikan.

Selanjutnya aspek analisis sebab-sebab masalah (analyze potential causes) berada pada tingkat tinggi. Secara keseluruhan siswa sudah mampu menemukan akar penyebab permasalahan yang terjadi. Hampir seluruh siswa memberikan pernyataan sebab-sebab masalah yang sudah berhubungan dengan permasalahan yang ditemukan pada wacana, dan memberikan gagasan yang masuk akal. 
Berdasarkan hasil wawancara dalam menganalisis penyebab utama terjadinya suatu masalah siswa mengembangkan gagasan sendiri berdasarkan pengetahuan dan pengalaman yang mereka peroleh. Hal ini sejalan dengan pendapat Charles dan Laster dalam Kaur (2008) bahwa yang dapat mempengaruhi problem solving skills seseorang karena faktor pengalaman, faktor kognitif maupun efektif. Namun masih ada dari mereka yang kurang dalam memahami konsep menganalisis.

Aspek Mengidentifikasi kemungkinan solusi (identify possible solutions) berada pada tingkat sangat tinggi. Secara keseluruhan siswa sudah mampu menentukan solusi-solusi alternatif melalui pemahaman sendiri yang dapat membantu

memecahkan masalah. Wulansari (2017) bahwa keterampilan dalam memilih solusi ini berhubungan dengan pemahaman siswa dalam menganalisis dan memahami isi bacaan agar dapat menentukan mana saja yang dijadikan sebagai alternatif solusi problem solving yang tepat.

Berdasarkan hasil wawancara, siswa dalam menemukan solusi alternatif didasarkan pada permasalahan yang pernah mereka temui di lingkungan maupun pengetahuan yang mereka peroleh dari sekolah maupun lingkungan luar siswa. Namun ada siswa yang memberikan solusi tidak didasari dengan pengetahuan dan pengalaman mereka, mereka memberikan pernyataan yang tidak masuk akal dan tidak sesuai dengan masalah yang sedang dihadapi.

Selanjutnya, aspek Memilih solusi terbaik (select the best solution) berada pada tingkat tinggi. Siswa secara keseluruhan sudah mampu untuk memilih solusi yang tepat sesuai dengan saran solusi-solusi yang sudah dijabarkan. Kemampuan memilih solusi berhubungan dengan pemahaman siswa dalam menganalisis dan memahami isi bacaan agar dapat menentukan mana saja yang dijadikan sebagai alternatif solusi problem solving yang tepat (Wulansari, 2017).

Hasil wawancara yang diperoleh bahwa siswa dalam memilih solusi terbaik sesuai dengan solusi-solusi alternatif yang telah dijabarkan. Pemilihan solusi ini didasarkan pada besar atau kecil suatu masalah dan cara yang efektif serta sesuai dengan masalah yang terjadi. Namun ada juga siswa yang masih memilih solusi tetapi tidak ada dalam solusi-solusi alternatif yang dijabarkan siswa.

Aspek menyusun rencana tindakan (develop an action plan) berada pada tingkat cukup, hanya sebagian siswa yang mamou menyusun rencana tindakan. Dalam tahap ini, siswa cenderung kurang tepat dalam merancang suatu tindakan yang disesuaikan dengan solusi yang mereka pilih, terutama dalam merancang tahap-tahap untuk melakukan suatu tindakan. Seharusnya untuk melakukan penyelesaian terhadap masalah yang terjadi siswa harus mampu untuk memiliki keterampilan dan pengetahuan dalam merancang strategi yang tepat sesuai tahap-tahapnya. Hal ini sejalan dengan pendapat Ismail dan Atan (2011) menyatakan bahwa siswa harus mampu merancang dan melaksanakan strategi serta memiliki pengetahuan tentang prosedur penyelesaiannya.

Melalui wawancara diperoleh bahwa siswa dalam menyusun rencana tindakan masih banyak mengalami kesulitan karena kurangnya kemampuan untuk memahami dalam mengurutkan tahapan dalam membuat suatu perencanaan. Dari keseluruhan siswa dalam menyusun rencana tindakan banyak yang tidak sesuai dengan solusi terbaik yang 
telah dipilih. Dan banyak dari mereka menyusun rencana tindakan yang tidak masuk akal. Padahal seharusnya rencana tindakan harus sesuai dengan solusi yang dipilih dan berurut agar tercapai apa yang diinginkan.

Mengimplementasikan dan mengevaluasi tindakan (implement solution and evaluate progress) termasuk kedalam aspek yang rendah dibanding aspek yang lain. Hal itu terjadi karena siswa hanya sedikit yang mampu untuk menerapkan dan mengevaluasi tindakan yang telah disusun untuk memecahkan suatu masalah. Kebanyakan dari mereka hanya memberikan solusi yang menurut asumsi mereka tepat, tetapi dalam melaksanakan tindakan solusi mereka masih kurang, karena kurangnya kepedulian mereka. Karena hal tersebut maka ketercapaian problem solving skills masih dianggap kurang. Berdasarkan wawancara dengan siswa, kebanyakan dari responden tidak mampu melakukan tindakan solusi dan tidak pedulinya mereka terhadap tindakan tersebut. Ada beberapa siswa merasa acuh taka acuh dengan masalah yang terjadi.

Berdasarkan hasil penelitian yang diperoleh pada aspek memilih solusi terbaik juga sejalan dengan hasil penelitian yang dilakukan Desliana (2018) bahwa pada aspek memilih solusi terbaik siswa memperoleh persentase $79 \%$, menunjukkan hampir keseluruhan siswa mampu memilih solusi terbaik. Hal ini sesuai dengan pendapat Juliyanto, dkk (2013) bahwa pada anak kelas VIII SMP sampai X SMA anak menentukan solusi berdasarkan kesimpulan yang ditarik dan hasil pengujian hipotesis. Namun apabila pengambilan keputusan yang tidak tepat, akan mempengaruhi kualitas hasil dari problem solving yang dilakukan (Paidi, 2011).
Oleh karena itu, berdasarkan hasil analisis data mengenai problem solving skills siswa kelas X di MAN Bintan dapat dilihat dari keseluruhan siswa mampu menguasai seluruh aspek problem solving skills. Namun, masih perlu adanya upaya dalam meningkatkan problem solving skills. Penting sekali setiap guru menerapkan pembelajaran problem solving kepada siswa hal ini diharapkan agar siswa terlatih untuk aktif berpikir, menganalisis, informasi yang diterima, mengolah data, dan akhirnya menyimpulkan. Sesuai dengan pendapat Anderson dikutip oleh Ulya (2016) bahwa problem solving merupakan keterampilan hidup yang melibatkan proses menganalisis, menafsirkan, menalar, memprediksi, mengevaluasi, serta merefleksikan.

\section{SIMPULAN DAN SARAN}

Berdasarkan hasil penelitian ini dapat disimpulkan bahwa rerata problem solving skills siswa pada materi lingkungan di kelas X MAN Bintan berada pada tingkat kategori tinggi. Hal ini menunjukkan bahwa secara umum siswa mampu memecahkan masalah terkait lingkungan dengan langkah-langkah problem solving secara baik. Langkahlangkah tersebut yaitu mendefinisikan masalah, menganalisis sebab-sebab masalah, memilih solusi terbaik, dan merencanakan tindakan. Namun, pada langkah terakhir yaitu mengimplementasikan solusi dan mengevaluasi perkembangan, siswa belum mampu melakukan dengan baik. Dengan demikian, perlu dilakukan upaya untuk meningkatkan problem solving skills siswa, terutama dalam mengimplementasikan solusi dan mengevaluasi perkembangan . 


\section{UCAPAN TERIMAKASIH}

Penulis mengucapkan terimakasih kepada kepala MAN Bintan yang telah mengijinkan melakukan penelitian di sekolah tersebut. Penulis berterima kasih kepada Ibu Azza Nuzullah Putri, S.Pd., M.Pd. dan Ibu Erda Muhartati, S.Si., M.Si. atas diskusinya yang bermanfaat. Selanjutnya ucapan terima kasih juga penulis sampaikan kepada Ibu Elfa Oprasmani, S.Pd., M.Pd. yang telah memvalidasi instrumen penelitian.

\section{DAFTAR PUSTAKA}

Arikunto, S. (2009). Prosedur Penelitian Suatu Pendekatan Praktik. Edisi Revisi 6. Jakarta: Rineka Cipta.

Chang, Richard Y., \& Kelly, P.Keith.

(2003). Langkah-Langkah Pemecahan Masalah. Jakarta: Lembaga Manajemen PPM.

Depdiknas. (2016). Permendikbud No 22 Tahun 2016 Tentang Standar Isi. Jakarta: Depdiknas.

Desliana, Mira. (2018). Kemampuan Pemecahan Masalah Siswa Kelas X SMAN 4 Tanjungpinang Berdasarkan Gaya Belajar Model David Kolb. Skripsi Pendidikan Biologi. Universitas Maritim Raja Ali Haji. Tanjungpinang.

Ismail, S dan Atan Abreza. (2011). Aplikasi Pendekatan Penyelesaian Masalah Dalam Pengajaran Mata Pelajaran Teknikal Dan Vokasional Di Fakulti Pendidikan UTM. Journal of Educational Psyhology and Conunseling. Vol. 2 No.1, 113-114.

Juliyanto, dkk. (2013). Perkembangan Pola Pemecahan Masalah Anak Usia Sekolah Dalam Memecahkan Permasalahan Ilmu Pengetahuan Alam. Jurnal Pendidikan Fisika Indonesia. ISSN 1693-1246.

Kaur, Berinderject. (2008). Problem Solving In The Mathematics Classroom (secondary). Singapore: National Institude of education.

Mellisa. (2018). Analisis Kemampuan Pemecahan Masalah Mahasiswa Program Studi

journal homepage : http://journal.univetbantara.ac.id/index.php/JBL/
Pendidikan Biologi FKIP UIR Pada Mata Kuliah Fisiologi Tumbuhann Tahun Ajaran 2015/2016. Jurnal Pembelajaran Biologi. Pekanbaru, Vol 1(2).

Nasution. (2009). Kurikulum Dan Pengajaran. Jakarta: Bumi Aksara.

OECD. (2016). PISA 2015 Results in Focus. New York: Columbia University.

Paidi. (2011). Model Pemecahan Masalah dalam Pembelajaran Biologi di SMA. Artikel Jurusan Pendidikan Biologi, FMIPA UNY.

Pratiwi, Gadis. (2014). Deskripsi Kemampuan Pemecahan Masalah Siswa Pada Konsep Pencemaran Lingkungan. Artikel Pendidikan Biologi. Fakultas Kegurauan dan Ilmu Pendidikan, Universitas Lampung.

Ulya, Himmatul. (2016). Profil Kemampuan Pemecahan Masalah Siswa Bermotivasi Belajar Tinggi Berdasarkan Ideal Problem Solving. Jurnal Konseling Gusjigang, Vol. 2(1).

Wulansari, Dian Nurmala. (2017). Perbedaan Kemampuan Pemecahan Masalah Siswa antara Model Pembelajaran PBI dan CPS pada Konsep Keanekaragaman Hayat. Skripsi. Pendidikan Biologi Universitas Islam Negri Syarif Hidayatullah Jakarta. 